\title{
LA POLÍTICA EN LA CIVILIZACIÓN CAPITALISTA
}

Autores: Aylin Patricia Pertuz Martínez (1)

\section{RESUMEN}

$\mathrm{E}^{\prime}$ l siglo XX es un período de grandes cambios en lo político, económico, social, tecnológico y ambiental. En los campos político, económico y social, el siglo apropia las ideas de importantes pensadores, inclusive desde mediados del siglo XIX, que analizan las transformaciones y los problemas de una sociedad que evoluciona sin cesar. El objetivo de esta revisión teórica es analizar el desarrollo del pensamiento político de los autores clásicos y contemporáneos de la teoría social, y, en ella, el fenómeno de la globalización en el mundo capitalista. El estudio concluye que en el campo político existen diversas concepciones desde la teoría social clásica y contemporánea, como la extinción del Estado, la división de poderes, el Estado como relación de dominación, el análisis del campo político como exclusión, la propuesta de la tercera vía. La sociedad avanza en la globalidad, pero también existen fuerzas que intentan hacer frente a la globalización.

Palabras claves: Teoría Social, Política, Globalización, Sociedad capitalista

\section{ABSTRACT}

$\mathrm{T}$ he twentieth century was a period of great change in the political, economic, social, technological and environmental. In the political, economic and social fields, the appropriate century ideas of important thinkers, including the mid -nineteenth century, analyzing the changes and problems in a constantly changing society. The main purpose of this revision is to analyze the development of political thought from classical and contemporary authors of Social Theory, and in it, the phenomenon of globalization in the capitalist world. It is concluded that there are different concepts from classical and contemporary social theory, the elimination of the state, the division of powers, the State as a relationship of domination, the analysis of the political field as exclusion, the third way. World globalization continues, but also there forces opposed to globalization .

Keywords: Social theory, Politics, Globalization, Capitalist Society

(1)Administradora de Empresas, Magistra en Administración de Empresas, Especialista en Gestión Pública, Doctoranda en Ciencias Sociales Mención Gerencia; Docente de planta Universidad de Sucre; aylin.pertuz@unisucre.edu.co 


\section{LA POLÍTICA EN LA CIVILIZACIÓN CAPITALISTA}

\section{INTRODUCCIÓN}

$\mathrm{E}$ ste artículo tiene como objetivo analizar el desarrollo del pensamiento político en autores de la teoría social, clásica y contemporánea, incluyendo el fenómeno de la globalización en la sociedad capitalista, para lo cual se efectuó una revisión de la literatura, desde los años 90s del siglo XX, hasta estos últimos años del siglo XXI, la cual comprende artículos de revista científicas, libros y documentos de estudio de instituciones. Su carácter es analítico interpretativo.

Comprende tres grandes capítulos. El primero, señala el aporte de los pensadores de la teoría social clásica en el ámbito político. Los ítems de este capítulo corresponden al pensamiento político en Karl Marx, Emili Durkheim, Max Weber, Theodor Adorno, Max Horkeimer y Alfred Zchütz. El segundo, muestra las distintas concepciones de la política en la teoría social contemporánea, tratándose en los distintos ítems a Anthony Giddens, Pierre Bourdieu, Jurguen Habermas, Niklas Luchman y Arendt. El tercero, trata el tema de la sociedad capitalista y el fenómeno de la globalización. Los ítems de este capítulo son: globalización e integración, formas de integración, sociedad global vs sociedad local, globalización vs fragmentación, la sociedad global y el Estado, la gobernabilidad y la democracia, el poder político planetario frente a la autodeterminación de los pueblos. Finaliza con las conclusiones.

\section{EL APORTE DE LOS PENSADORES A LA TEORÍA SOCIAL}

T a "gran teoría social" ha reconocido importan$\Delta$ tes transformaciones en su historia, las cuales se relacionan "pero no dependen mecánicamente de otras en los niveles de la economía, la política, la cultura" (de la Garza, s.f: 1).
En el caso de los clásicos, estos descubren "el núcleo explicativo" de las cuestiones en la que reposa "el problema del conocimiento de la realidad social". El haber llegado a las raíces del problema les permite resistir la "prueba del tiempo" (Pérez, s.f: 19). Dentro de la teoría social, los aportes provienen de autores como Marx, Durkheim, Weber, Adorno, Horkeimer, Shütz.

\section{Karl Marx. La política y el Estado.}

La teoría marxista, es el tipo de teorías denominada de "amplio rango o espectro", es decir, posee una perspectiva histórica más generalizada, intentando responder preguntas acerca de los grupos de sociedades, las causas de su evolución y los cambios estructurales (Larraín, 2014). Karl Marx (1818-1883), en su ideario político, hace énfasis en la sociedad, el hombre y no en el Estado. En sus inicios, Marx toma la democracia como una forma de gobierno en donde el hombre es el centro y no la sociedad, aunque posteriormente la teoría marxista termina por negar el Estado (Colombo,s.f:).

Con base en Hegel, el Estado y la política se constituyen en el "ámbito integrador universal, capaz de neutralizar la lógica destructiva y el egoísmo capitalista"; en cambio, Marx observa, inicialmente, que, en las sociedades de clases, la política es antes que todo el espacio de "la alienación, de la ilusión y el engaño" (La Crítica a la Filosofía del Estado de Hegel y La Crítica a la Filosofía del Derecho de Hegel). Marx rechaza la idea de que el Estado está aparte o es superior a los individuos (Ozollo, 2005).

En su juventud, Marx expone que el Estado es "una representación, mandante de asuntos particulares. No es la constitución quien crea al pueblo sino el pueblo el que crea la constitución, la democracia debe ser la esencia de toda constitución". A diferencia de Hegel, quien plantea que la "soberanía del monarca encarna la nacionalidad", para Marx, si el soberano fuese "realmente la soberanía del Estado", tendría que aparecer entonces como "otro Estado" separado del pueblo (Ozollo, 2005). 
LA POLÍTICA EN LA CIVILIZACIÓN CAPITALISTA

Para Marx, el Estado, es entonces, "el conjunto de las instituciones políticas, en que se concentra la máxima fuerza imponible y disponible en una determinada sociedad, pura y simplemente como una superestructura respecto a la sociedad prestatal, que es el lugar donde se forman y se desarrollan las relaciones materiales de existencia y, en cuanto superestructura, destinado a desaparecer a su vez en la futura sociedad sin clases" (Bobbio, 1999:5)

En su libro La ideología Alemana, concibe al estado como "la forma bajo la que los individuos de una clase dominante hacen valer sus intereses comunes y en la que se condena a toda una sociedad civil de la época". El estado es un instrumento para que una clase económica mantenga su poder sobre la sociedad; en este caso la burguesía, consolidada después de la edad media, en pleno convencimiento del concepto de propiedad privada (Colombo, s.f:).

En Marx, el Estado moderno, admite la separación del ciudadano político del ciudadano del Estado. De esta separación surge la burocracia, que manifiesta la conciencia y la voluntad del Estado. El individuo debe comportarse como un ciudadano real del Estado, para lo cual debe "realizar una abstracción de su ser civil para luego, afirmar su ciudadanía política en su pura y simple individualidad" (Colombo, s.f: 9; citando a Rubel, s.f:73).

Un problema esencial para Marx es la relación entre el Estado y la propiedad privada, considerando que están muy ligados; así la "constitución política es una expresión de la propiedad privada". Las industrias y los comercios son propiedad privada de las corporaciones; los cargos del gobierno son propiedad de "clases privada"; el Estado y la nacionalidad son propiedad del monarca. De esta manera, el Estado tiene como objeto cuidar a la propiedad privada y a los intereses de sus dueños contra los que nada tienen (Ozollo, 2005).

En el Manifiesto Comunista, en el Estado burgués como dominio de clase, el poder es definido como "el poder organizado de una clase para la opresión de otra". Cuando Marx señala el estado como dominación, o como la "dictadura de una clase sobre otra", el objeto de estudio es el Estado burgués. Como se expresó anteriormente, en La Ideología Alemana, manifiesta que el Estado "no es otra cosa que la forma de organización que los burgueses se dan por necesidad, tanto hacia el exterior como hacia el interior, a fin de garantizar recíprocamente su propiedad y sus intereses" (Bobbio, 1999:7).

El paso de la dictadura de la burguesía a la dictadura del proletariado, no puede realizarse solo con la conquista del poder del Estado, sino que el aparato del Estado que sirvió a la burguesía debe ser destruido y las instituciones deben, por lo tanto, sustituirse por otras diferentes. Entre las características del nuevo Estado, se indican las siguientes: supresión del ejercito permanente y de la policía armada sustituyéndose por un pueblo armado; funcionarios elegidos y controlados por el pueblo, responsables y revocables; jueces elegibles y revocables; sufragio universal para elección de delegados con mandato los cuales son revocables; abolición de la separación de poderes puesto que la comuna debía tener un trabajo legislativo y ejecutivo al mismo tiempo; amplia descentralización para reducir las funciones del gobierno central. En la transformación de la sociedad capitalista a la sociedad comunista, hay un periodo de transición cuyo Estado es la "dictadura revolucionaria del proletariado" (Bobbio, 1999).

Cuando Marx postula la extinción del Estado, está reivindicando dos cosas: "la recuperación por la sociedad de la función política, que aparece bajo la forma del Estado como poder socialmente alienado, y la simultánea pérdida por la sociedad de su naturaleza meramente civil, que hace de ella un agregado de seres sin orientación” (Sánchez, 1981:132). 
LA POLÍTICA EN LA CIVILIZACIÓN CAPITALISTA

El pensamiento de Emili Durkheim

Emili Durkheim (1858-1917), en los años 1883 y 1884, como profesor de filosofía realiza diversas disertaciones en cuanto a la moral y otros temas. Plantea que los deberes cívicos son un problema propio de la moral, la cual es una forma de "disciplina social como modalidad de inculcación de valores sociales sólidos". La moral se subdivide en "moral teórica" y "moral práctica". La "moral cívica" como parte de la "moral práctica" es aquella que "determina los deberes que tienen los individuos cuya reunión forman una nación" (Inda, 2008).

Para Durkheim, la organización de la sociedad necesita que los "intereses comunes" estén a cargo de personas cercanas a la función, las cuales constituyen el gobierno. El gobierno posee diferentes poderes. Para que estos poderes no sean negativos o peligrosos, deben estar divididos en distintas clases de personas, lo cual se constituye en el "principio de la división de poderes". De acuerdo con el autor, y, retomando a Montesquieu, los poderes que constituyen el gobierno son: el legislativo, el ejecutivo y el judicial. Cada uno de estos poderes tiene como función hacer las leyes, aplicarlas y castigar con penas la violación de las mismas (Inda, 2008).

La función del gobierno, según Durkheim, es la de salvaguardar a los ciudadanos, los unos de los otros, y guiar a la sociedad al logro de "su propio fin". Aclara, que cada sociedad tiene su propio fin o sus propios intereses. Para la dirección de su "propio fin", la sociedad delega a ciertos individuos a ese poder de dirección (Inda, 2008).

Durkheim, esboza su concepto del Estado a través de cuatro elementos: a) el papel de la ciencia y de la especialización en la definición de las funciones del estado; b) el Estado nace de la sociedad por medio de la delegación, es decir, la sociedad existe primero para luego dar origen al Estado, motivo por el cual el Estado está sujeto a un "control perpetuo" por parte de la nación que lo ha creado; c) cada na- ción tiene sus propios intereses, aunque el Estado tiene dos funciones esenciales como son cuidar a la ciudadanía y guiar a la sociedad al logro de su propio fin; d) la identificación Estado-gobierno, cuyos contornos coinciden, estando compuestos por los poderes legislativo, ejecutivo y judicial. Importante anotar que, para Durkheim, el Estado, como producto de la nación, no puede tener poder absoluto, puesto que "no puede disminuir la personalidad del ciudadano" (Inda, 2008:144).

El autor rechaza dos teorías acerca de las funciones del gobierno en las sociedades modernas: la teoría socialista y la teoría liberal o individualista. La primera considera que los ciudadanos "pertenecen al Estado" al dejar a un lado su individualidad cuando se incorporan a la sociedad, en el que el gobierno conduce a dicha sociedad a un fin, del cual los miembros pueden estar de acuerdo o no. Durkheim, mira esta teoría como "inmoral", puesto que el individuo es sólo un instrumento para que la sociedad llegue a un fin determinado. Acerca de la teoría liberal, sostiene que los fines individuales son lo más importante. El Estado protege a los ciudadanos e interviene o ejerce su autoridad cuando existen amenazas al respeto de la libertad individual. Aunque esta concepción no deja a un lado "la ley moral que boga por el respeto al individuo, es contraria a los intereses de la sociedad" (Inda, 2008: 145).

\section{Max Weber, la acción social y la política.}

A diferencia de Marx y Durkheim, Max Weber (1864-1920), centra en el hombre su estudio de la acción social. Retorna a la idea de Kant en cuanto a la "finitud del sujeto en un universo infinito" y por lo tanto, "todo conocimiento conceptual de la realidad por parte de este individuo limitado, se apoya en el supuesto de que sólo una parte finita de esa realidad forma el objeto del estudio científico" (Martínez, s.f: 1). 
LA POLÍTICA EN LA CIVILIZACIÓN CAPITALISTA

De acuerdo con el autor existen cuatro tipos de acción social, como aplicación de su método "idealtípico": a) acción social de acuerdo a los fines, que se caracteriza por el uso de medios adecuados para el logro de un fin específico; b) acción social racional de acuerdo a valores, en el que la conducta de un sujeto (os) tiende a la puesta en marcha de un "valor transcendente"; c) acción social afectiva o emocionalmente determinada, caracterizada por la emoción y los estados de ánimo; d) acción social tradicional, que se manifiesta en la costumbre establecida. Estos tipos son abstracciones puras a los que se puede aproximar la acción real en mayor o menor grado (Opazo, 2012).

Max Weber es el pensador que a principios del siglo XX le da un "mayor acabado" a la nueva forma de pensar la realidad de las relaciones políticas; en especial sus aportes acerca de la burocracia, la dominación, la autoridad, la legitimidad, el carisma. En la sociología política del autor se expone la teoría de la "dominación burocrática", considerado éste, como el gran producto de la "racionalidad política de occidente". También es occidental el concepto de funcionario especializado, eje del Estado moderno y de la economía europea (Fleitas, 2005).

La burocracia, comprende todas las estructuras del Estado moderno, de las instituciones, de las estructuras de las empresas capitalistas. En contrario se tiene a la dominación patriarcal, cuya dominación se basa en la "tradición", o, en otras palabras, la cosa se ha hecho siempre de la misma manera. En la dominación burocrática las normas se crean en forma racional, acuden a la "legalidad abstracta" y se basan en un "ejercicio técnico" (Fleitas, 2005).

Para Weber, la política es "cualquier género de actividad directiva autónoma". El Estado es una relación de dominación de hombres sobre hombres, que se sostiene por medio de una violencia legítima... basada en la legalidad, en la creencia en la validez de preceptos legales y en la competencia objetiva fundada sobre normas racionalmente creadas". La racionalidad política de Weber está basada en los fundamentos metodológicos de su sociología, es decir, el enunciado de los "Tipos Ideales", que son "hipótesis o probabilidades típicas de la realidad, conceptos abstractos y ahistóricos" (Fleitas, 2005: 235), tal como se anotó para el caso de la acción social.

La política, en lo teórico, tanto en el interior como en el exterior, es una lucha entre las naciones, las clases o los individuos. Solamente, los individuos que tienen la voluntad de poder participan en la lucha, siendo éstos los capacitados para la política. Weber, hace hincapié en el "carácter diabólico del poder y en los sacrificios que exige el Estado de poder". En cuanto al nacionalismo e imperialismo, reconoce las reivindicaciones nacionales, las aspiraciones de las naciones consientes de sí mismas, de tener autonomía o independencia. Aunque el desmembramiento de Europa central en Estados aparentemente nacionales que tendrían que abarcar obligatoriamente minorías nacionales, no le parecía propicio ni realizable (Aron,1981).

Para Weber, la política de poder entre las naciones, en donde las guerras son una manifestación "normal y un resultado inevitable", no es considerada "como una supervivencia de tiempos ya pasados o como una negación del esfuerzo humano en pro de la cultura, sino como una forma, entre otras formas en definitiva crueles, de lucha por la vida entre las clases y las naciones". Esta visión tiende a reducir el alcance de la oposición entre la paz y la guerra, entre la disputa económica de los pueblos y la lucha por el poder de los Estados (Aron, 1981).

\section{Theodlor W. Adorno y la Illustración}

Theodor Adorno (1903-1969), realiza en el transcurso de su vida académica varias contribuciones a la teoría social en compañía de autores como Hannah Arendt (1906-1975) y Max Horkheimer (1895 - 1973). 
LA POLÍTICA EN LA CIVILIZACIÓN CAPITALISTA

Con Max Horkheimer, analiza el "carácter dialectico de la Ilustración dentro del contexto de la relación entre la racionalidad y la realidad social". La racionalidad es el concepto de ilustración. Para los autores, "ILUSTRACIÓN" es la "racionalidad dominante imbricada en cada aspecto de la sociedad burguesa moderna". "Ilustración", en cambio, es la "racionalidad universal orientada hacia la liberación y la oposición de la dominación". La ilustración cumple con "la función de liberación y oposición de la dominación" a través de la "memoria de la naturaleza en el sujeto". El proceso mediante el cual la "promesa de liberación del miedo de la naturaleza", expuesta por el movimiento de la "ilustración" que ha estado en la racionalidad dominante, se muestra en los siguientes desarrollos: a) una nueva epistemología; b) separación entre sujeto, naturaleza y sociedad, y c) el progreso social (Galindo, 2003).

El concepto de Ilustración tiene como centro a la razón (Rojas, 1999). Para la Escuela de Frankfurt la razón, no es para el "pensamiento moderno sólo la diferencia específica del hombre, tal como venía caracterizada por la tradición filosófica occidental, sino que se expande hasta convertirse en la capacidad que le permite al hombre emanciparse gradual y progresivamente de la naturaleza" (Damiani, 2002:73).

La "dialéctica negativa" se expresa en la dialéctica de la ilustración como un enfoque filosófico y no como herramienta científica. "La dialéctica negativa se convierte en una postura que deja a salvo a la razón frente a los acontecimientos; deviene en crítica permanente incluso sobre sí misma y frente a la historia; en este sentido es negativa, al no buscar ni aceptar su transformación en doctrina o en nuevo mito" (Rojas, 1999:84).

El principio de la "no identidad" es la base del pensamiento de Adorno, es decir, "la dialéctica negativa; no identidad entre la conciencia verdadera e intereses políticos del proletariado; no identidad entre sujeto e historia, entre conocimiento y conformación de las condiciones sociales de producción. Los conceptos de "fantasía exacta, mímesis y constelación", se convierten en los recursos técnicos para la elaboración de explicaciones de los hechos sociales. Se asocian y disocian en forma dialéctica los conceptos, haciendo uso de lo freudiano y lo marxista en cuanto al inconsciente y al materialismo dialectico (Rojas, 1999).

Los autores Adorno y Horkheimer, a principios de los cuarenta presentan varios sucesos en sus vidas que les son impactantes al tener antecedentes familiares judíos, razón por lo cual el Instituto de Frankfurt -al cual pertenecen - abre sedes en Estados Unidos e Inglaterra: la barbarie nazi, la Unión Soviética de Stalin con un socialismo de Estado de carácter autoritario que eliminaba cualquier contradicción; el ascenso económico de los Estados Unidos, y la alienación de la población norteamericana, el aumento del consumismo, y la "uniformidad de pensamiento combinada con efectos de amnesia instantánea provocados por la explosión de los masa media". Estos sucesos se consideran no avances de las sociedades sino en "retrocesos de la razón, en la precipitación de la barbarie" (Rojas, 1999: 83).

Adorno junto con Hannah Arendt, son reconocidos por el estudio del fenómeno del totalitarismo, el cual había sido estudiado desde la Alemania nazi y la Unión Soviética estalinista. Adorno, y otros autores como Friedrich Pollock y Max Horkheimer señalan que un "completamente desarrollado sistema fascista - en el caso históricamente concreto del sistema nacional-socialista - tiende a anular la primacía marxista de los factores económicos sobre los factores políticos" (Henao, 2011, citando a Dubiel, 1985:78). En la Dialéctica de la ilustración, Adorno y Horkheimer, indican que dado que la Ilustración no es "capaz de ver su propio lado oscuro", se encuentra en él la posibilidad de surgimiento del totalitarismo: "la incorporación del hombre como parte de la naturaleza que se debe dominar mediante la creciente y absoluta extensión del principio utilitario de la razón instrumental como forma de relación social". 
LA POLÍTICA EN LA CIVILIZACIÓN CAPITALISTA

Estos dos autores explican el eje central del antisemitismo, como eje político- cultural del régimen totalitario. En lo que respecta a lo social y económico, dicen que el antisemitismo tuvo una función importante en la consolidación del sistema capitalista, dado el "ocultamiento de la dominación de la producción”. Así, los judíos se convirtieron en los sujetos sobre el cual recayó, las frustraciones que el sistema había producido en las masas (injusticias, mentiras, robos) (Henao, 2011).

La inequidad en el sistema se produce debido a la división capitalista del trabajo, así como por los efectos y diferencias entre las personas que producen y las que reciben. Así, los judíos jugaron un papel importante en la descarga de las frustraciones puesto, que ellos hacían la conexión entre productores y distribuidores. Al ser los "mercaderes responsables de la distribución de las mercancías eran susceptibles de ser considerados responsables de la explotación" (Henao, 2011:81).

\section{Max Horkeimer: La Teoría Crítica}

El pensamiento de Max Horkeimer (1895-1973) en sus primeros años se caracteriza por el estudio de las bases culturales del capitalismo y la modernidad. En su primera teoría crítica, al igual que Adorno, el "deslinde metodológico" que aspira a hacer Horkheimer, no es sólo el romper con la "percepción positivista de una totalidad constituida sin conflictos", sino que es necesario comprender la presencia de una dinámica llena de conflictos, en la cual "la cultura producida por la acción entre los sujetos y la resistencia existente de éstos frente a las instituciones representan y reproducen en consecuencia modelos unilaterales de vida". Así, la primera teoría crítica del autor es un rechazo al "establecimiento cientificista" en el que se aspira a eliminar el "ámbito cultural" y se privilegia la "función instrumental-racional", y la sociedad se convierte, de esta manera, en una "lógica auto sustentada" que puede actuar dejando de lado a los se- res humanos (Alarcón, 2002).

Su segunda teoría crítica, trata acerca de las formas de la "sociabilidad industrial capitalista", la cual ha impuesto a las personas, el ascetismo, la acumulación, el egoísmo, que se convierten en factores para las posibilidades de desarrollo y así obtener el progreso moral en el mundo. La identidad política es un sustituto de lo que ha perdido la naturaleza humana a lo largo de la modernidad. Para Horkheimer, Adorno y Marcuse, la "humanidad reivindicable" comprende dos principios del "proyecto ilustrado": la libertad de conciencia y la autonomía del sujeto, que se expresan en la "solidaridad colectiva". Ello indica que una ética política sólo es posible "en tanto pueda denunciarse la naturaleza fragmentaria y egoísta que se ha interiorizado dentro de una sociedad que hasta ahora sólo se articula alrededor de la auto-conservación y que ya no persigue la transformación de sí misma" (Alarcon, 2002:11).

\section{El mundo de la vida de Alfred Schuitz.}

En la teoría social expuesta por Alfred Schütz (1899- 1959), el mundo del día a día constituye la realidad inminente, un mundo al alcance en el que se llevan a cabo los proyectos de las personas. Es un mundo ofrecido a la experiencia e interpretación, en el que se desarrollan las acciones e interacciones de las personas y que se experimenta como un "mundo intersubjetivo", es decir compartido por "Otros", mediante las relaciones personales. Pero también hay

“experiencias que trascienden el ámbito finito de sentido del mundo de la vida cotidiana y se refieren a otros ámbitos finitos de sentido, a otras realidades o, para usar el término acuñado por William James, a otros subuniversos, tales como el mundo de la teoría científica, de las artes, de la religión, de la política, pero también de las fantasías y los sueños". A estos se accede a través de la simbolización (Shutz, 1974, citando en Acevedo, 2011). 
LA POLÍTICA EN LA CIVILIZACIÓN CAPITALISTA

Las personas son capaces de trascender la vida cotidiana por medio de símbolos, y también son capaces, en casos especiales, de cambiar la actitud natural y cambiar a diferentes esferas de la realidad. El autor amplía su visión del mundo de la vida, de forma tal que incluya todas "las modificaciones de actitud y de estado alerta", es decir, cada una de las "tensiones propias de la conciencia" (Dreher, s.f; citando a Dreher 2003: 143; Schütz/Luckmann 1989: 21).

De acuerdo con Schütz las experiencias que trascienden la vida cotidiana son la organización social y política y las instituciones sociales, que son representadas por "apresentaciones particulares". Por lo tanto, las colectividades sociales y las relaciones institucionales no corresponden al entorno del "sentido de la realidad de la vida cotidiana", sino que son "construcciones del pensamiento de sentido común que tienen su realidad en otros subuniversos que sólo se aprehenden simbólicamente". Entonces, los "hombres" se relacionan con la sociedad simbólicamente y la "experiencia de la organización social y política se da mediante apresentaciones simbólicas" (Acevedo, 2011:88).

Para Schütz, la acción política tiene como fines la conquista del ideal de igualdad de oportunidades, entendiéndose ésta en un sentido objetivo, para lo que es necesario afectar el orden social. Esta transformación se daría desde el "orden pre-político del mundo de la vida en cuyas estructuras encontraría sus condiciones constitucionales, que se anclan en la actitud natural y la conditio humana" (Belvedere, 2011: 75).

Srubar, expone que en la fenomelogía de Shutz la política - "orden particular de sistemas de tipificaciones y de significatividades" - estaría basada en un mundo "socio-cultural previo", de manera tal que "la base del orden político sería un orden social pre-político". De acuerdo con el pensamiento de Schütz respecto al "conocimiento socialmente compartido" y la tesis de reciprocidad de perspectivas, Srubar indica que las representaciones compartidas y de un universo de sentido compartido, es lo que facilita o hace posible la política. La política surge cuando el conocimiento compartido y socialmente aceptado se pone en cuestión (Acevedo, 2011: 88).

\section{EL APORTE DE LOS PENSADORES A LA TEORÍA SOCIAL CONTEMIPORÁNEA}

] a teoría social contemporánea está representa$\mathcal{A}$ da en autores como Giddens, Habermas, Bourdieu y Luchman, cuyo pensamiento se sintetiza a continuación. Dado que la política es el eje de este trabajo, en este punto se incorpora el pensamiento de Arendt, a pesar de haber sido criticada por subestimar la cuestión social. Su pensamiento hace parte de la teoría política contemporánea.

Anthony Giddlens: La teoría de la estructuración y la tercera vía.

Anthony Giddens (nacido en 1938), autor muy reconocido por su "teoría de la estructuración", así como por su concepción de la "tercera vía", observándose en él distintas etapas en su pensamiento. En la teoría de la estructuración pretende superar el dualismo existente entre "teorías de la acción (de orientación subjetivista) y teorías de la estructura (alineadas en una posición objetivista)", para lo cual propone una concepción "dual de estructura". El núcleo de la teoría se compone de los conceptos de estructura, sistema y dualidad de la estructura (Cambiasso, 2011).

Giddens define la estructura como "[...] conjunto de reglas y recursos organizados de manera recursiva, está fuera del tiempo y del espacio, salvo en sus actualizaciones y en su coordinación como huellas mnémicas y se caracteriza por una "ausencia del sujeto" [...]". El Sistema Social lo constituyen "[...] relaciones reproducidas entre actores o colectividades, organizadas como prácticas sociales regulares $[\ldots]$ ". La dualidad de la estructura, es el intento de "síntesis entre estructura y acción", puesto que las estructuras y los agentes no son fenómenos independientes uno del otro, lo cual no significa un dualismo sino una dualidad. 
LA POLÍTICA EN LA CIVILIZACIÓN CAPITALISTA

Afirma Giddens, en la "Teoría de la estructuración, el momento de producción de la acción es también un momento de reproducción en el contexto en que desarrolla la vida social" (Cambiasso, 2011: 8). "Agencia" es la idea de Giddens en posición a la concepción funcional - estructuralista de "actor" en el que se mira a éste como un elemento pasivo o sometido a las condiciones circunstanciales o estructurales. En su lugar, Giddens piensa que los seres humanos tienen condiciones y capacidades que le permiten superar las limitaciones, actuando en una forma diferente "en una fase establecida de comportamientos", además no son las intenciones de las personas lo importante sino su capacidad para hacer cosas. Otro aspecto que trata Giddens es el concepto de "reflexividad", que consiste "en la capacidad de los individuos para ejercer una especie de control racional de su propia conducta". No debe confundirse con "auto-conciencia", sino que es una constante monitoría de la vida personal y social (Infante, 2007).

En su estudio acerca del capitalismo, es de anotar que Giddens también caracteriza los movimientos sociales y las revoluciones, partiendo del siglo XVIII con los casos de Estados Unidos y Francia. Según el autor, "la revolución y la democracia se han convertido en sinónimos para cierto pensamiento social". Pero las revoluciones deben distinguirse de los golpes de Estado y de las rebeliones. En los golpes de Estado se observa la ausencia de movimientos sociales de masa, así como la falta de "orientación hacia cambios o reformas profundas" (Infante, 2007).

Otro de los aspectos tratados por el autor es el tema del poder, el cual se observa en su trabajo sobre la violencia y el Estado -nación. Así, por ejemplo, una de las características de los Estados modernos es el incremento del poder sobre los individuos la expansión y sofisticación de los mecanismos de vigilancia. Otro fenómeno, es el de la globalización, que hace parte de la cuatro "formas fundamentales de cambio de las sociedades actuales", vale decir: la globalización de la vida social, la urbanización moderna, cambios en los "patrones demográficos", revoluciones y movimientos sociales (Infante, 2007).

La "tercera vía" es la idea de Giddens de hacer compatibles el crecimiento económico con el desarrollo social, que no es un camino medio entre el liberalismo y el comunismo. En el enfoque tradicional la Socialdemocracia no da respuesta a los cambios dados después de la Segunda Guerra, y el neoliberalismo conduce a un camino más desigual, produciendo más marginados de la vida social. Por ello señala: "La meta general de la política de la tercera vía debería ser ayudar a los ciudadanos a guiarse en las grandes revoluciones de nuestro tiempo: la globalización, las transformaciones de la vida personal y nuestra relación con la naturaleza" (Prati, 2000).

\section{El pensamiento político en Pierre Bourdieu.}

La concepción de Pierre Bourdieu (1930-2002) está influida por la "teoría de clase" de Carlos Marx y la "teoría de capas" de Max Weber, aspectos que unifica y combina. Para Bourdieu el "espacio social pluridimensional en el cual el mundo social es reproducido", deja a un lado las ideas tradicionales de jerarquía social basada en la imagen de una sociedad arrumada en una pirámide en la que cada clase mantiene cierta posición debido a sus condiciones materiales (Meichsner, 2007).

El autor establece distintas formas de capital, siendo estos el económico, social, cultural, y el simbólico. El capital económico y social son los que más contribuyen en la construcción del "espacio social". Los actores se reparten el espacio social con la siguiente lógica: En primer lugar, los grupos sociales, según su capital se encuentran en un "orden jerárquico en la dimensión vertical", según la cantidad de capital económico, social y cultural que posean. En segundo lugar, la relación relativa de las diferentes formas de capital mantiene a los grupos entre sí. De esta manera, los actores se ubican en una "dimensión horizontal" dependiendo de su capital económico y social. 
LA POLÍTICA EN LA CIVILIZACIÓN CAPITALISTA

El cambio de posición en el "espacio social" tiene que ser "pagado, siempre con trabajo, esfuerzo y sobre todo con tiempo" (Meichsner, 2007: 5).

Un concepto de Bourdieu es el "poder simbólico" que consiste en una forma de "violencia ejercida sobre uno o varios actores que, lo permiten por la producción y reproducción de las categorías de percepción existentes" (Meichsner, 2007:8)

En el campo político Bourdieu se inspira en Max Weber, Robert Michels y Antonio Gramsci. Entre los aspectos tratados están las estrategias comunicativas utilizadas para influir a la opinión pública y "verificar la línea que separa a los "profanos" de los políticos profesionales". Dice Bourdieu que el campo político se organiza alrededor de dos polos derecha e izquierda; liberal o conservador -. Este campo lo define como "un sistema de distancias entre estos dos polos de tal manera que todas las actividades y discursos dentro de este campo pueden ser interpretados de una manera relacional, es decir como un juego de oposiciones y distinciones". El campo político, asimismo está interpuesto en "el gran total del mundo social". Las luchas tienen como finalidad cambiar las relaciones de fuerza que se dan en la estructura del campo (Meichsner, 2007).

El campo político, comprende a los "profesionales" y a los "profanos"; mientras más excluyente sea, el campo se vuelve monopolio de los profesionales, por ello se tiende a escuchar que, de política, sólo los políticos pueden hablar, sólo ellos tienen la competencia. En la mayor monopolización "la política es propiedad de los políticos". "El campo político descansa sobre la exclusión, la desposesión política". Por su parte, el campo social tiene normas las cuales deberán ser cumplidas por quienes ingresen a él. Estas normas, requisitos, virtudes ... permiten a los "agentes sociales" experimentar el juego en el campo. (Velazco, s.f: 7).

Bourdieu expresa que la política "produce e impone su propia representación por sí misma", a partir de los "políticos mediadores", que son los asesores de imagen, lo que hacen el "marketing político", y los politólogos que se dedican a asesorar a los políticos. Ningún político profesional podría ejercer esta actividad sino tuviese un cortejo de "analistas, asesores y políticos mediadores". También es necesario comprender que los políticos no actúan en relación a sus electores sino en términos de sus “oponentes" (Velazco, s.f:).

Jurguen Habermas: La teoría de la acción comunicativa.

El pensamiento político de Jurguen Habermas (nacido en 1929) tiene en la visión ético política un eje central de su análisis acerca de la crisis "del Estado social" y las "Utopías sociales". Para Hebermas se está dando una transformación de la conciencia occidental, en el que las ideologías, como el nacionalismo, principalmente, dejan de ser el centro de las actividades colectivas y ceden su espacio a los valores de la "Ilustración", expresados en los postulados de la universalización de la democracia y de los derechos humanos" (Beluche, 2007).

Claro está, que los valores de la Ilustración surgieron con el nacionalismo, el cual tiende hacia la "identificación de una herencia cultural común con un Estado nacional concreto", cuyo modelo era el Estado nacional democrático proveniente de la Revolución Francesa. En el nacionalismo coinciden en "una unidad contradictoria, libertad y autodeterminación política, soberanía popular del ciudadano y soberanía nacional del Estado". Según Habermas, en la conciencia nacional existen dos contradicciones: "las orientaciones universalistas de valor del Estado de Derecho y la democracia" y el "particularismo de una nación que se delimita a si misma frente al mundo externo, por otro"; aspectos que producen tensiones que se resuelven con la conformación de una "conciencia histórica nacional” (Beluche, 2007:12). 


\section{LA POLÍTICA EN LA CIVILIZACIÓN CAPITALISTA}

Esta contradicción se vive hasta el nacionalismo de Hitler y Mussolini, que rompe el equilibrio dando pie "al egoísmo nacional de las ataduras a los orígenes universalistas del estado constitucional democrático". Luego de este "shock fascista" se produce una reflexión en donde el énfasis en la "identidad colectiva" ya no son los nacionalismos estatales sino los valores democráticos que vienen de la Ilustración (Beluche, 2007).

Habermas se distancia completamente de la teoría marxista, aunque hay autores que consideran que Habermas es un continuador. Así, por ejemplo, frente al socialismo estudiantil y sus viejos "mitos de izquierda", el primer dogma que el autor propone para ser revisado es que el «capitalismo intervenido y regulado por el Estado», estuviese "ante problemas insolubles a la hora de emplear productivamente el capital". Para Habermas la teoría de Marx acerca de la crisis del capitalismo mediante la teoría del valor - trabajo, ya no es sostenible (Sotelo, 1997). En su primera etapa intelectual, Habermas pretende redefinir la problemática filosófica política en el capitalismo tardío, resultado un "proyecto de Reconstrucción del Materialismo Histórico". En su segunda etapa, la reflexión la realiza en la fundamentación de una "Teoría de la Acción Comunicativa", como eje estratégico de "religitimización de la sociedad capitalista", a partir de un diagnóstico de "la colonización que sobre el mundo de la vida ha ejercido el derecho, generando un proceso de desintegración acelerada a su interior". Posteriormente lo complementa con la Ética Discursiva (Mejía, 2011).

Uno de los aspectos tratados por el autor se refiere al "fracaso de las Utopías sociales", refiriéndose a la experiencia socialista de los Estados obreros de Europa Oriental y otras regiones. Habermas desestima las experiencias socialistas de estos Estados y coloca como nuevo camino el "Estado Social" de Occidente. Para Habermas, los socialismos de Estado fracasaron por la "utopía de la sociedad del trabajo", con el que se esperaba lograr la "emancipación humana", gracias al desarrollo de las fuerzas productivas y "la colectivización de los medios de producción (Beluche, 2007).

Habermas hace una crítica de Adorno y Horkheimer, puesto que considera que estos tienen una visión sesgada, al pensar que la modernidad es sinónimo de "racionalidad autoconservadora". La "razón sustancial" personificada en tiempos anteriores en la religión y la metafísica, queda atrás, pero se transforma en una "razón procedimental", que será "la depositaria de los fundamentos de validez de la ciencia y de los principios de la vida social" (Carretero, 2006:14).

Es de anotar que en la obra teoría de la acción comunicativa, el autor desarrolla "los fundamentos racionales de una teoría de la acción capaz de superponerse al subjetivismo e individualismo propios de la filosofía moderna de la época". Construye una teoría "comprehensiva de la sociedad y de la comunicación social" que parten de los conceptos de "sistemas" y del "mundo de la vida". Por último, consigue construir una teoría crítica de la modernidad a partir de su proyecto sugiriendo nuevas ideas para su reconstrucción (Garrido, 2011).

\section{Niklas Luchman: La teoría de los sistemas socia-} les.

Niklas Luchman (1927-1998) es considerado unos de los sociólogos más originales y controvertidos del siglo XX. En su obra trata una teoría que pretende ser universal y que es aplicable a todo fenómeno social. La "Teoría de los Sistemas Sociales" comprende distintos tipos de sistemas y las condiciones que les permiten surgir, a partir de la complejidad que pretenden reducir (Arriaga, 2003).

Luhman describe a la sociedad moderna como un sistema, que está conformado, no tanto por individuos, sino por comunicación. "Se diferencia en subsistemas funcionales cerrados a través de códigos especializados, como son: los sistemas político, económico, religioso, artístico o jurídico (Urteaga, 2010). 
LA POLÍTICA EN LA CIVILIZACIÓN CAPITALISTA

Uno de los estudios realizados por Luhman se refiere al Estado benefactor. A partir de la teoría de los sistemas, el autor plantea que el Estado benefactor es una forma del sistema político, es decir, "una programación del sistema que pretende reducir la complejidad del entorno. Si hay una crisis de este modo de programación, ésta se debe entender como una distorsión en las relaciones sistema/entorno, es decir, como la incapacidad del sistema político para reducir la complejidad del entorno". La crisis del modelo benefactor es una crisis que hace parte del sistema político; lo cual lo diferencia de otros autores como Habermas, Hobsbawm o Harvey, que proponen a las variables culturales o económicas como causas de la crisis (Gonnet, 2010).

Por lo tanto, si el Estado benefactor es "una distinción del sistema político", las bases de su crisis deben buscarse en el sistema como tal y no en el entorno. Para Luhman, el Estado benefactor entra en crisis por un "déficit de auto-reflexión del sistema político". Dicho déficit se relaciona con una inadecuada comprensión del sistema político dentro de la sociedad moderna, así como de sus formas de "observación y operación". El primero de los déficits se deriva de la "concepción centralista de la política". Es decir, pensar la política y el Estado como lugares favorecidos de "acción y observación de la sociedad", lo cual implica no reconocer la complejidad de la sociedad y la existencia de un número importante de sistemas sociales. El segundo déficit se debe a una "ausencia de reflexividad acerca de las posibilidades y limitaciones de las estructuras y los medios que dispone el sistema político para el desarrollo de sus acciones" (Gonnet, 2010: 310).

\section{Pensamiento político de Hanna Arendt.}

Hanna Arendt (1906 - 1975), es reconocida por su crítica al totalitarismo con todas las perversidades del "lugar público". El poder político según Arendt emerge de la misma acción. La política es inhumana cuando "se reduce a la jerarquía vertical del Estado", o de alguna fuerza que actúa como monopo- lio, lo cual es injustificable porque elimina la "pluralidad humana", que es abierta a la "singularidad" y a las diferencias en el espacio de una humanidad que "madura democráticamente". Para Arendt, se debe repensar "la condición política en función del poder de la igualdad humana", integrando el respeto a la singularidad de los seres humanos, que diferencia a unos de otros. El verdadero poder es consecuencia de una acción conjunta y compartida en el espacio y tiempo, determinados por las personas que se sienten tanto distintos como iguales (Zapata, 2006). En sus escritos, la autora pronostica la destrucción de la "mundanidad" y la pluralidad en sociedades de masas, a "causa de dejar la distinción humana en los espacios privados y subjetivos, lo que podría derivar en la minimización del espacio público y por tanto la pérdida de la capacidad de acción"' de las personas en él. La autora en su texto La condición humana, hace una crítica hacia la "vida contemplativa" que procede de los cuestionamientos sobre las guerras mundiales, la masificación de las sociedades con fuerte industrialización, el dominio sobre la naturaleza mediante la tecnología y la ciencia (Heras y Morales, 2013).

Toda la fuerza destructiva en "antipolítica", puesto que no sólo acaba con la vida humana sino el mundo donde se crea todo tipo de vida, es decir, humana y extrahumana, por lo tanto, la única actividad que constituye "un fin es si mismo es la acción política". El sentido de las personas está en la vida misma y en "la riqueza de la pluralidad", y las diferencias que se presentan en ésta. "Somos lo que hacemos, somos cuando actuamos e implica a otros, somos cuando hablamos y aparecemos ante los otros". De la misma forma: "somos cuando él otro nos reconoce y comprendemos que nuestro mundo son los otros" (Heras y Morales, 2013). La política es la búsqueda de la libertad humana (Gaytan, 2001), o en otras palabras, "la esfera del ser en común o el espacio público se estructura desde la libertad que constituye el fundamento de la política (Zapata, 2012). 
LA POLÍTICA EN LA CIVILIZACIÓN CAPITALISTA

\section{LA SOCIEDAD EN LA "CIVILIZACIÓN CAPITALISTA"}

A partir de la segunda mitad del siglo XX el mundo ve surgir una nueva sociedad mundial, presentándose en ella importantes cambios, que han desembocado en una sociedad global caracterizada por la mundialización, la transnacionalización, la inmediatez e instantaneidad de gran parte de las relaciones internacionales. La nueva sociedad mundial es universal y planetaria, heterogénea, compleja, interdependiente, global, desequilibrada, desigual, entre otras características (Del Arenal, 2002).

\section{Globalización frente a la integración.}

El despegue de la globalización en el siglo XX proviene de la crisis de la gestión de la economía con corte "keinesiano, nacional desarrollista o de planificación centralizada", que dio "funcionalidad política" al modelo neoliberal para la apertura de las economías nacionales. La globalización presenta una serie de oportunidades para las naciones, al ser una "promesa" de desarrollo y bienestar. Igualmente, la difusión de los derechos humanos esenciales, los cuales son la base para la convivencia en cualquier sociedad. Pero, la globalización también es vista, como un proceso que sólo beneficia a un grupo de naciones y, en ellas, al sector financiero internacional (Ensignia, 2008).

La integración económica se refiere a diversos procesos en que países cercanos geográficamente se comprometen a eliminar barreras económicas entre sí, lo que implica acuerdos comerciales que pueden extenderse a la liberalización comercial (Maesso, 2011).

La globalización unida a la integración, en su dimensión económica presenta oportunidades y retos.

La globalización "tiende a ser un proceso impulsor en la capacidad que tienen los actores de la economía global de mover bienes, servicios, dinero, per- sonas e informaciones". La integración económica está orientada a la eliminación de las barreras comerciales de bienes y servicios entre los distintos países, así como crear mercados complementarios (Jiménez, 2010). Aunque, la integración implica para un país renunciar a grados de libertad bajo la expectativa de mayores beneficios. Un ejemplo de ello es la Unión Europea, que es el mayor proceso de integración económica (Laborde y Veiga, 2010).

\section{Formas de la integración}

Existen diversas modalidades de integración económica, tales como: La zona de libre comercio, en donde los países que lo conforman eliminan todas las barreras arancelarias y no arancelarias entre ellos, pero tienen independencia en la política comercial en cuento al resto del mundo; la unión aduanera, en el que los países miembros, además de eliminar las barreras arancelarias, formulan una política comercial común con el resto del mundo; el mercado común, que al igual que la unión aduanera, se define la libre circulación en el interior, en cuanto a bienes, personas y capitales (Laborde y Veiga, 2010).

De igual forma están: la unión económica, en donde los países miembros, además de poseer los mismos derechos y obligaciones de un mercado común, establecen la unificación total de las políticas monetarias y fiscales; y, la integración política completa, en el que el área integrada se convierte en una única nación, manejando una autoridad central con un nivel jerárquico parecido al gobierno de una nación (Laborde y Veiga, 2010).

\section{Sociedad global frente a sociedad local}

La sociedad actual es una realidad global y local al mismo tiempo. Lo global se define como la globalidad económica que existe en estos momentos, aunque es entendido que existen otras formas como la de información, el medio ambiente, las drogas, el crimen, entre otras. En términos económicos, la actividad estratégica está organizada en "redes globales de decisión e intercambio". 


\section{LA POLÍTICA EN LA CIVILIZACIÓN CAPITALISTA}

Estas actividades funcionan como una unidad en el mundo, además de hacerlo en tiempo real. Lo local, se concibe como el centro que gestiona lo global (Gutiérrez, 1998).

La globalización, en las últimas décadas está en "conflicto con la forma de organización del Estado territorialista de la política" (Heinz, citado en Heinz y Arenas, 1994). Las Naciones Unidas, el FMI, el $\mathrm{BM}$, las empresas transnacionales, son más dinámicas que antes, y las ONG`s se han extendido por el mundo. En este último caso, debido a una necesidad internacional de regulación que no puede ser atendida por los Estado-Nación, por lo que se habla, entonces, como expresan algunos autores de un "Estado Internacional" o la "internacionalización del Estado". Empero, paralelo a la globalización, hay una revigorización de los nacionalismos, una revitalización de identidades de grupos étnicos, el regreso de sentimientos religiosos, fundamentalismos de distinta índole, así como una renovación del espiritualismo (Heinz y Arenas, 1995).

Lo local adquiere relevancia dependiendo de cómo se ubique en las dos percepciones de la "sociedad contemporánea": en una mirada, lo local no es un desafío relevante, en virtud a que las especificidades deben dar paso al avance de la "racionalidad globalizante". En otra perspectiva, lo local se encuentra en un lugar de privilegio articulado entre la "racionalidad instrumental" de los procesos de desarrollo y las identidades locales requeridas para activar dichos procesos (Arocena, s.f.). Ahora bien, sentirse dentro de una nación es un proceso consciente, en el que la persona tiene que darse cuenta. Esto es considerado como el sentido de pertenencia (Cabrera, Fernández, Ordoñez y Rosas (2005), citado en Pérez (2012).

Existen tres tendencias acerca del desarrollo local frente a la globalización: a) la afirmación de lo global frente a lo local; b) lo local como una alternativa ante los males de lo global; c) la articulación entre lo global - local, en una comprensión compleja de la sociedad actual (Arocena, s.f).
La globalización económica no puede generarse sin el apoyo de las bases territoriales, locales "conectadas en red y suministradoras de la riqueza globalizada". Sin embargo, se hace necesario, una serie de requisitos para que ello se presente. Las naciones pueden ser una limitante si están en contra de la total liberalización de las transacciones de tecnología, capital, flujo de personas, etc, aunque en su interior existen personas en territorios locales interconectados, quienes necesitan un conjunto de bienes y servicios para vivir en buena forma y ser productivos (Gutiérrez, 1998).

Al nivel mundial, el alto grado de interconexiones de las relaciones sociales ha conducido a "una realidad de análisis en el contexto de la sociedad global entre las múltiples realidades sociales locales". Ya existen las bases en aspectos regulatorios sin violencia o conflictos, sobre la justicia social y la individual. Aun así, los Estados se han abierto a la nueva economía sin proteger o apoyar a los empresarios, a la sociedad local, y en términos generales, se ha respondido a "la demanda de la economía global", desconociendo el rompimiento de la sociedad, la economía y "la cohesión de la agencia", derivados del proceso globalizador (García, 2006).

\section{Globalización frente a fragmentación}

Las relaciones internacionales se caracterizan por la existencia al mismo tiempo de dos tendencias: la globalización y la fragmentación. En la globalización se agrupa "las fuerzas centrípetas o integradoras" presentes en la comunidad internacional. La fragmentación, agrupa "las fuerzas centrífugas o dispersadoras", como una respuesta de los Estados y grupos sociales ante el dominio de la globalización. La fragmentación posee dos procesos que muestran esta tendencia: "la regionalización y la globalización” (García, 1998). 
LA POLÍTICA EN LA CIVILIZACIÓN CAPITALISTA

El "regionalismo contemporáneo" o "nuevo regionalismo" se define como "[...] el proceso por el que un área geográfica dada, diferentes actores - Estados, instituciones regionales, organizaciones sociales $-[\ldots]$ participan en una creciente red de interacciones económicas, culturales, científicas, diplomáticas, políticas, e incluso militares por la que se generan y comparten una serie de valores fundamentales" (G. Mace y Therien, 1996, citado en García, 1998:320). La globalización, hace referencia a la "toma de conciencia de las entidades locales, de la necesidad de adaptar su actuación a las exigencias de la globalización, y, en consecuencia, del incremento de su actividad internacional" (García, 1998:320). Así, los nuevos productos de las empresas, son el resultado de los "procesos de transnacionalización" de la industria, es decir, se abren los canales de distribución, se produce "para lo global desde lo local" (García, 2010).

La fragmentación, es utilizada por el movimiento antiglobalización y es fruto del aumento de la desigualdad en los últimos años, cuyas causas no se derivan únicamente del "mal funcionamiento de políticas económicas". Existen razones estructurales, sociales y morales que se deben tener en cuenta. De esta manera, "las desigualdades en renta podrían apuntar también desigualdades culturales que son en sí mismas positivas", pero la riqueza se mide en términos del P.I.B, lo cual es una visión estrecha, que no permite ver la "riqueza no monetarizable como la riqueza moral" (Pérez, 2001). La fragmentación también puede estudiarse desde el examen de lo que ha supuesto en "la consolidación del espíritu de la Ilustración" y en el desarrollo de "la modernidad, la aparición del yo como sujeto social primigenio". Dentro de los cambios sociales que ha generado la "cultura de la modernidad" se encuentra la pérdida de sentido comunitario y el auge del individualismo. Se presenta también, una fragmentación cultural donde la dignidad y la autonomía no se entienden ni se proponen de igual modo ante personas iguales en sitios distintos (Pérez, 2001).
La globalización y la fragmentación están interrelacionados, pero es la globalización el proceso que genera y arrastra a los otros. Cuando la regionalización y la globalización se han generado influyen sobre la globalización, puesto que al hacerle frente intentan, en forma parcial, modificar y reorientar su camino (García, 1998).

América Latina, por ejemplo, manifiesta tres procesos fundamentales en la política mundial: la globalización, la regionalización y el nacionalismo. Procesos que son "fuerzas superpuestas e interrelacionadas, a veces antagónicas y a veces no, pero nunca en armonía" (Kacowicz, 1998, citado en Kacowicz, 2008:113). De este modo la estrategia de América Latina respecto al resto del mundo está condicionada por la interacción de estas tres fuerzas: apertura al mundo (globalización), integración regional (regionalización), y fragmentación (regionalización externa y vínculos transregionales) (Kacowicz, 2008).

\section{Sociedlad global y el Estado}

En estos primeros años del siglo XXI, el Estado nacional y la identidad nacional, en la constitución de una sociedad moderna, pasan a estar en entredicho por las tendencias de la época. Por la globalización se habla de una "desnacionalización". La correspondencia de los espacios sociales, económicos, culturales establecidos por el Estado Nacional en los inicios del siglo XX, se remplaza por "la yuxta y sobreposición de múltiples circuitos" (Lechner, 2005).

Actualmente se evidencia la dificultad del Estado en la coordinación y regulación de la economía nacional - de la cual depende el empleo y los ingresos de la población-, así como en la obtención de los recursos tributarios necesarios para las inversiones, sin la provocación de fuga de capitales. 
LA POLÍTICA EN LA CIVILIZACIÓN CAPITALISTA

Los acuerdos de carácter internacional que van desde los de derechos humanos hasta los del medio ambiente, y en especial "las reglas de facto" establecidas por los grandes fondos de inversión tienden a disminuir "la soberanía interna y externa del Estado, lo cual puede hacer quebrantar su "eficiencia y su legitimidad". La globalización afecta la eficiencia del Estado en cuanto a sembrar un "proceso económico libre de turbulencias" y asegurar para cada persona "similares oportunidades de decidir su destino". De esta manera, el Estado tiene ante sí una mayor demanda de intervención, pero de igual forma ve restringido su accionar (Lechner, 2005).

De acuerdo con Stobe Talbot (1992), secretario de Bill Clinton, "en los próximos cien años [...] la nacionalidad, como la conocemos será obsoleta; todos los Estados reconocerán una sola autoridad global”. De igual forma expresa "Todos los países son básicamente acomodos sociales, ajustes a circunstancias cambiantes. No importa que tan permanentes y hasta sagrado parezcan en un momento dado, de hecho, son artificiales y temporales" (Talbot, 1992:70; citado por Robinson, 2007:102). Al igual que esta afirmación, otros autores a finales del siglo $\mathrm{XX}$ consideraron que el Estado nación llegará a su fin al igual que "la corporación sin Estado". Se arguye un nuevo concepto: el "Estado transnacional" (Robinson, 2007).

El Estado transnacional implica tres proposiciones: a) la globalización económica tiene sus contrapartes en la formación transnacional de clase y la aparición del Estado transnacional, que se constituye en "la autoridad colectiva para la clase dominante global"; b) El Estado nación no tiene su primacía ni desaparece, sino que va siendo modificado $u$ absorbido por el Estado transnacional cuya estructura es mucho más grande; c) El "Estado transnacional emergente institucionaliza las nuevas relaciones de clases entre el trabajo global y el capital global" (Robinson, 2007:106).

De acuerdo con Habermas, existen fenómenos que no pueden ser manejados adecuadamente por el Estado nación, tales como el problema ecológico, el crimen organizado mundial, movilización constante de capitales de una parte del mundo al otro lado. Como estos problemas han desbordado la capacidad del Estado nación, ésta ha tenido que modificarse creando alianzas con otros Estados nación, para establecer grupos de cooperación basados en intereses comunes. Figuran aquí las alianzas regionales, en un proceso paulatino desvanecimiento de del concepto de nacionalidad, adquiriendo más fuerza el concepto de "transnacionalidad" (Mejía, 2011).

Con el proceso de globalización el Estado ha perdido su "capacidad de producción de significado", lo cual ha sido remplazado por instituciones del gobierno mundial y las "industrias culturales" (Benavides, 2015).

\section{Gobernabilidad y democracia}

La gobernabilidad se analiza en la literatura desde distintos tópicos: como una "propiedad, una cualidad, o un estado de la relación de gobierno". Por lo general en las definiciones son comunes los elementos de eficacia, legitimidad y estabilidad en el ejercicio del poder político como variables básicas de la gobernabilidad. Respecto a la "eficacia/ eficiencia en el ejercicio del poder político" y de la gestión gubernamental, estas se consideran claves para la "gobernabilidad del sistema social", lo cual guarda relación con la conceptualización de "propiedad". La legitimidad está unida a "la tradición del buen gobierno": el Estado justo y la mejor forma de gobierno, lo cual se relaciona con el concepto de "calidad". Por último, la estabilidad que pone su atención en el "problema del orden político", así un sistema será más estable en la medida que pueda adaptarse a los cambios del entorno nacional e internacional, en lo económico, social y político (Camou, 2001). 
LA POLÍTICA EN LA CIVILIZACIÓN CAPITALISTA

Con base en la definición de Norberto Bobbio (1984), una forma de gobierno es considerada democrática si cumple con las siguientes condiciones: a) los sujetos involucrados en la toma de decisiones pertenecen mayoritariamente a la población adulta; b) el proceso de toma de decisiones se rige por el "principio de la mayoría"; c) se garantiza un conjunto de libertades básicas que permiten a los "sujetos involucrados" a presentar o elegir opciones políticas sin coacción (Camou, 2001).

La Comisión Trilateral (años 70s) asocia el concepto de gobernabilidad con la "sobrecarga de demandas sociales frente al Estado" (Huntington, et al., 1975, citado en Filmus, 2005). Con esta interpretación, la ingobernabilidad está asociada a la falta de eficacia de los Estados para dar respuesta a los reclamos de la sociedad, dentro de un marco de condiciones económicas, así como a la pérdida de confianza de la ciudadanía de los políticos y las instituciones democráticas al no ver cumplidas sus demandas (Rojas, 1995, citado en Filmus, 2005).

Bajo esta posición conservadora se expone que es la ampliación de la democracia al permitir mayores demandas de la sociedad civil frente al Estado, se "deslegitima como sistema". Desde la concepción de la Comisión Trilateral, gobernabilidad y democracia son dos términos contradictorios "[...] un exceso de democracia significaría un déficit de gobernabilidad; una gobernabilidad fácil sugiere una democracia deficiente..." (Rojas, 1995, citado en Filmus, 2005).

Las limitaciones externas de la gobernabilidad democrática, se originan en las dificultades de la democracia "para integrar los diferentes centros de interés y de poder en una sociedad compleja", a diferencia de las limitaciones internas que provienen del propio funcionamiento de las instituciones del sistema democrático. Las democracias tienen la dificultad de "unificar la diversidad de intereses sociales" con base en el "interés público" de la ciudadanía, además porque no existe una única ciudadanía sino múltiples ciudadanos; así como el reto de articular las diferentes modalidades de "representación de intereses" con los senderos de las organizaciones y los "mecanismos políticos tradicionales". Los desafíos de la gobernabilidad de la democracia, ya no provienen de la "existencia de sistemas políticos alternativos, sino de la necesidad de corregir y perfeccionar las instituciones de la democracia" con el objeto de superar ciertos problemas relacionados con su funcionamiento $\mathrm{y}$ "complementar sus mecanismos de representación y agregación de intereses con el fin de superar las limitaciones externas". Se hace necesario generar una "estructura institucional" que frene los déficits generados por "la fragmentación de poder" sin un "liderazgo unificador" o tensiones entre los distintos poderes, o por un alargue de la fase de deliberación de la toma de decisiones (Camou, 2001).

También es necesario que las "instituciones clásicas de la democracia representativa sean complementadas con esquemas de agregación de intereses, de mecanismos de toma de decisiones", de acuerdos y "pactos" que brinden al gobierno, a los "grupos estratégicos" y a los ciudadanos, de medios eficaces y "legítimos de intervención política en los problemas de la sociedad". El logro de una gobernabilidad se basa en "una serie de acuerdos básicos" entre las élites dirigentes, los grupos sociales estratégicos, y la mayoría ciudadana, con el fin de resolver los problemas del gobierno. La estabilidad de estos acuerdos y su carácter previsible y aceptado, se podrá hablar de un "paradigma de gobernabilidad", lo cual no quiere decir que no existan conflictos de diversa índole (Camou, 2001).

Perspectivas alternativas de la gobernabilidad desarrolladas por autores como Tomassini, Schmitter y Coppedge (1993), Lechner (1995), Arbós y Giner (1993), Flisfish, Rojas, Torres y Alcántara, estudian el concepto como un "fenómeno sistemático". Se plantea un debate acerca de los distintos actores sociales en función de la generación de condiciones que permitan la gobernabilidad democrática. 
LA POLÍTICA EN LA CIVILIZACIÓN CAPITALISTA

Por lo tanto, la gobernabilidad ya no es un asunto de "ingeniería en el ámbito de la cúpula del Estado", sino que pasa a ser un "proceso más complejo donde deben interactuar un conjunto de actores". De esta manera, la gobernabilidad democrática no es únicamente la capacidad de un gobierno para ser obedecido por sus propiedades, sino de la capacidad de todos los "actores políticos estratégicos" para moverse dentro de unas reglas de juego sin amenazas permanentes de ruptura que propaguen la incertidumbre en la sociedad (Rojas, 1995, citado en Filmus, 2005).

Un término reciente es el de gobernanza, el cual desde la visión de Rhodes y Kooiman (citando en Canto, 2012), se define en los siguientes términos: no sólo el gobierno gobierna, también lo hacen las "redes autoorganizadas" y los mercados, aunque el Estado no ha perdido ese monopolio; las redes son el espacio favorecido del gobierno de los "actores"; la responsabilidad y la rendición de cuentas de las "intervenciones se extienden a los actores públicos y privados, en tanto comparten la función de gobernar". Pero, la gobernanza, tiene sus puntos negativos frente a la democracia, como puede ser el "conflicto entre los principios de la rendición de cuentas en una democracia representativa y la participación en redes que pueden ser abiertas sin estar formalmente sujetas a la rendición de cuentas". Además, la gobernanza como redes "autoorganizadas" es un reto a la gobernabilidad, puesto que las redes se convierten en autónomas y resisten al gobierno central (Rhode, 1996, citado en Canto, 2012).

Poder político planetario frente a la lucha por la autodeterminación de los pueblos.

La historia de la autodeterminación inicia con los 14 puntos de Woodrow Wilson en 1918, ideas que provienen de referentes teóricos de Locke, Mill y Acton; defendida por personajes reconocidos del siglo XX y recogida como "principio" en los artículos 1 y 2 y en el 55 de la carta de las Naciones Unidas. Igualmente, reconocida en 1996 en el Pacto internacional de Derechos Civiles y Políticos, en su artículo 1 (Merladet, 2011). En 1970 las Naciones Unidas adoptan dos textos fundamentales: la Resolución 2621y la Resolución 2625. En esta última, figura "el principio de la igualdad de derechos y de la libre determinación de los pueblos" (Bermejo, s.f). El derecho de autodeterminación es la autonomía proyectada al pueblo o al grupo humano. En cierta forma, la autonomía dota de fundamento a la autodeterminación (Martínez, 2007).

La autodeterminación se invoca como un derecho, pero esto es confuso. Conforme al "principio" de autodeterminación, se tiene, que "éste no solo suplanta al derecho, sino que sustituye a toda teoría política; se supone que no se necesita argumentar aquello a lo que se tiene derecho de antemano [...], por ello un derecho sin teoría política solo cabe defenderlo con la fuerza ciega" (Martínez,2007: 334).

De acuerdo con los pactos de derechos, "para el logro de los fines, todos los pueblos pueden disponer libremente de sus riquezas y recursos naturales". De igual forma, dentro de los pactos de derechos civiles y políticos, y los de carácter económico, social y cultural, la autodeterminación, se relaciona en su "sentido originario" con la posibilidad de que un pueblo pueda dotarse de una organización política propia (Martínez, 2007). Ahora bien, en sentido jurídico - político, o cultural, pueblo es sinónimo de nación, en cambio donde pueblo se connota a masas populares, no puede utilizarse el término nación, en este caso pueblo (plebs o populus), se refiere a los "excluidos de la dirección de una sociedad" (Payero, 2014). Debido a la ideologización ha "nacido una mística del sacrosanto derecho de autodeterminación" que se ha infiltrado en muchas luchas independentistas con serios peligros, como por ejemplo "la falsa politización de la autodeterminación como derecho, es decir su alienación, su substitución al proceso concreto, material y social (en todas sus expresiones organizadas) de autodeterminación de un pueblo" (Raveli, 2009: 8). 


\section{LA POLÍTICA EN LA CIVILIZACIÓN CAPITALISTA}

Ahora bien, la autodeterminación no debe reducirse al "derecho de autodeterminación". Una "autodeterminación real" se evidencia en un proceso de "desarrollo del poder popular", mas no por una ley, o por una "nueva constitución de Estado", tal como lo demuestran algunas "naciones ya reconocidas como tales, como pueblos específicos", pero aún sometidos. "Un derecho reconocido, y hasta asumido en el "derecho internacional", pero que no permite ninguna auto-determinación en los hechos" (Raveli, 2009).

La autodeterminación es una readaptación y continuación de la idea moderna de soberanía del Estado. Pero en la "perspectiva planetaria" sólo hay lugar para una "soberanía limitada" (Martínez, 2007).

El reconocimiento y aplicación del "derecho de autodeterminación", presente en los pactos internacionales, que en teoría debería de haberse 'convertido en derecho positivo dentro de los Estados, ha encontrado resistencias y grandes objeciones por parte de los "Estados plurinacionales" afectados y por parte de la comunidad internacional que no desea tener complicaciones con modificaciones del "status quo", en especial, si esto molesta a los Estados influentes en un contexto internacional. La ambigüedad de los grandes Estados, ha procurado que la declaración universal del derecho de la autodeterminación se vea neutralizado en las declaraciones y pactos, con las afirmaciones paralelas del "derecho a la integralidad territorial de los Estados", entre otras, que les permiten invocar los convenios de acuerdo a su particular conveniencia. Por encima de una comunidad internacional que se resiste a reconocer los derechos de los más débiles, se aspira que, a futuro, ningún Estado pueda dejar de reconocer el derecho de autodeterminación (Caño, 2002).

Uno de los grandes problemas de la autodeterminación está en la formación de un Estado independiente, lo cual recibe grandes críticas puesto que esto se considera "un proyecto trasnochado", en espacios actuales de integración. Otro inconveniente, radica en la independencia económica, puesto que una sociedad de "economía mundializada, planetaria o interdependiente" no se puede hablar de este este tipo de independencia, ya sea en el campo monetario, fiscal, laboral, educativo, pensiones, etc (Caño, 2002). 


\section{LA POLÍTICA EN LA CIVILIZACIÓN CAPITALISTA}

\section{CONCLUSIONES}

$\mathrm{L}$ a teoría social ha recibido importantes aportes de autores que provienen de distintas disciplinas de cono-

cimiento, quienes han tratado de describir, comprender o interpretar los problemas de la sociedad; al mismo tiempo han brindado a la comunidad científica propuestas para dar solución a los problemas de carácter económico, político y social, cada uno de ellos desde su realidad.

La teoría social muestra distintas perspectivas desde el siglo XIX, con autores como Karl Marx, Emili Durkheim, Max Weber, considerados clásicos. En el siglo XX se destacan Theodor Adorno y Max Horkheimer, pertenecientes a la Escuela de Frankfurt. Otro autor reconocido es Alfred Schütz

En el campo político, algunas ideas se refieren a la extinción del Estado por parte de Marx; el principio de la división de poderes en Durkheim; el Estado como relación de dominación de acuerdo con Weber; el surgimiento del totalitarismo a partir de la Ilustración según Adorno; una ética política posible con el cambio de la sociedad en Horkeimer; la política y su finalidad, es decir, la conquista de la igualdad de oportunidades, de acuerdo con Schütz.

En la línea contemporánea de la teoría social hay varios autores como Giddens, Bourdieu, Habermas y Luchman. Giddens y su estudio de la violencia y el Estado- nación, así como la propuesta de la Tercera Vía; Bourdieu y el análisis del campo político como exclusión, y las estrategias comunicativas de los políticos; Habermas y su examen de la crisis del Estado Social y las Utopías Sociales, Luchman y la crisis del Estado Benefactor y sus causas en el sistema político. Arendt considera la política como la expresión de la libertad humana.

Dos fenómenos de carácter económico y social que cruzan la vida de varios de los pensadores de la Teoría social son el capitalismo y la globalización; y, la consecuente sociedad que se ha formado y transformado en ellos, en especial en el siglo XX. El estudio de las bases del capitalismo de acuerdo con Horkeimer; el análisis del capitalismo enfatizando los movimientos sociales y las revoluciones en Giddens; la revisión de algunos dogmas del capitalismo según Habermas, son algunos ejemplos teóricos.

Hoy, existe una nueva sociedad, enmarcada en el fenómeno de la globalización, la sociedad global, permeada por las relaciones internacionales, en la que también se presentan situaciones complejas que procuran hacer frente a la globalización, como la sociedad local, la fragmentación, la autodeterminación, entre otros, y en donde lo político sufre importantes cambios, en temas como la gobernabilidad, la democracia, y la naturaleza del Estado. 
LA POLÍTICA EN LA CIVILIZACIÓN CAPITALISTA

\section{Referencias bibliográficas}

Acevedo, M. (2011). Aportes de la teoría social de Alfred Schütz para pensar la política y la acción colectiva. Trabajo y Sociedad, 15 (17), 83-94. Recuperado de http://www.scielo.org.ar/scielo.php? script $=$ sci_arttext\&pid $=$ S151468712011000200007

Alarcón, V. (2002). Max Horkheimer: Los Reductos de la Crítica. Recuperado de http:// www.uam.mx/difusion/revista/oct2002/

alarcon.html

Arocena, J. (s.f). El desarrollo local frente a la globalización. Recuperado de http:// www.fts.uner.edu.ar/catedras03/politica_social/ documentos/desarrollo_local_y_regional/ el_desarrollo_local_frente_a_la_globalizacion_Aro cena.pdf

Aron, R. (1981). Max Weber y la política de poder. Papers. Revista de Sociología, 15, 33-53. Recuperado de http://ddd.uab.cat/pub/ papers/02102862n15/02102862n15p33.pdf

Arriaga, E. (2003). La Teoría de Niklas Luhmann. Convergencia , 32, 277-312. Recuperado de http:// www.infoamerica.org/documentos_pdf/

luhmann_01.pdf

Beluche, O. (2007). Pensamiento político de Jurgen Habermas. Kaosenlared.net. recuperado de http:// old.kaosenlared.net/noticia/pensamiento-politicojrgen-habermas

Belvedere, Carlos (2011). La constitución de lo político a partir del mundo de la vida en la obra de Alfred Schutz. Investigaciones Fenomenológicas, 3. Recuperado de http://www.uned.es/dpto_fim/ InvFen/InvFen_M.03/pdf/05_BELVEDERE.pdf

Benavides, F. (2015). Soberaranía, globalización y la constitución de significado. Justicia, 27, 153-166. Recuperado de http://www.scielo.org.co/pdf/just/ n27/n27a09.pdf

Bermejo, R. (s.f). El derecho de autodeterminación de los pueblos a la luz del derecho internacional. Recuperado de http://www.wshrw.org/Documentos/ espa $\% \mathrm{C} 3 \% \mathrm{~B} 1 \mathrm{ol} / \mathrm{An} \% \mathrm{C} 3 \% \mathrm{~A} 1$ lisis/

Bermejo_Ref_ONU_Autodet.pdf

Bobbio, N. (2001). Ni con Marx ni contra él. Fondo de Cultura Económica, 132-147. Recuperado de http://www.cholonautas.edu.pe/modulo/upload/ rebobio1.pdf

Cambiasso, M. (2011). La teoría de la estructuración de Anthony Giddens: un ensayo crítico. Instituto de Investigaciones Gino Germani, VI Jornadas de Jóvenes Investigadores. Recuperado de http:// webiigg.sociales.uba.ar/iigg/ jovenes_investigadores/6jornadasjovenes/EJE\% 209\%20PDF/eje9_cambiasso.pdf

Camou, A. (1996). Gobernabilidad y democracia. UNAM. Recuperado de http:// biblio.juridicas.unam.mx/libros/libro.htm?l=501

Canto, R. (2012). Governanza y democracia. De vuelta al río turbio de la política. Gestión y política píblica, 21 (2), 333-374. Recuperado de http:// www.scielo.org.mx/pdf/gpp/v21n2/v21n2a2.pdf

Caño, J. (2002). Nacionalismo, autodeterminación e independencia. Recuperado de http:// www.euskoalkartasuna.org/es/nacionalismoautodeterminacion-e-independencia/

Carretero, A. (2006). Jürgen Habermas y la Primera Teoría Crítica. Encuentros y Desencuentros. Recuperado de http://www.facso.uchile.cl/publicaciones/ moebio/27/carretero.pdf

Colombo, Rafael (s.f). El estado en la teoría social clásica. Una aproximación al pensamiento de Karl Marx y Emili Durkheim. Rebelión. Recuperado de http://www.rebelion.org/docs/28637.pdf

Damiani, Alberto (2002). La mitología como hermenéutica política: Horkheimer lector de Vico. Cuadernos sobre Vico, 13,14, 73-93. Recuperado de http://www.institucional.us.es/revistas/vico/ vol.13-14/5.pdf 
LA POLÍTICA EN LA CIVILIZACIÓN CAPITALISTA

Del Arenal, C. (2002). la nueva sociedad mundial y las nuevas realidades internacionales: un reto para la teoría y para la política. Recuperado de http:// www.mexicodiplomatico.org/lecturas/La\% 20Nueva\%20Sociedad\%20Mundial_Realidades\% 20Inter_Un\%20reto.pdf

De la Garza, E. (s.f). ¿Hacia dónde va la teoría social? Recuperado de http://www.google.com.co/url? $\mathrm{sa}=\mathrm{t} \& \mathrm{rct}=\mathrm{j} \& \mathrm{q}=\& \mathrm{esrc}=\mathrm{s} \&$ source $=$ web $\& \mathrm{~cd}=11 \& \mathrm{ved}$ $=0 \mathrm{CBsQFj}$ AAOAo\&url=http $\% 3 \mathrm{~A} \% 2 \mathrm{~F} \%$

2Fdocencia.izt.uam.mx\%2Fegt $\% 2$ Fpublicaciones $\%$

2Fcapituloslibros\%2FHacia\%2520donde\%

$2520 \mathrm{va} \% 25201 \mathrm{a} \% 2520 \mathrm{Te}$ \% $\% 25 \mathrm{EDa} \%$

2520So-

cial.pdf\&ei $=$ VcmyU9v0NI3ksASz_4GoDA\&usg= AFQjCNHD6A_burtrQX71 AavFZn7zrSgRg\&bvm=bv.69837884,d.cWc

Dreher, J. (s.f). Fenomenología: Alfred Schutz y Thomas Luckmann. Recuperado de Recuperado de http://www.socialsciencesmeditationnews.org/ weblog/wp-content/uploads/2013/08/

Fenomenologia-y-Sociologia-Drecher.pdf

Ensignia, Jaime (2008). Globalización e Integración Regional: los desafíos para el progresismo latinoamericano y chileno. Fundación Friedrich Ebert. Recuperado de http://library.fes.de/pdf-files/bueros/ chile/05452.pdf

Filmus, D. (2005). Gobernabilidad democrática: conceptualización. Revista Aportes Andinos 13, . Recuperado de http://www.uasb.edu.ec/padh/ centro/pdfs13/daniel\%20filmus.pdf

Fleitas, R. (2005). La sociología política de Max Weber. STVDIVM. Revista de Humanidades, 11, 227-240. Recuperado de dialnet.unirioja.es/ descarga/articulo/2049970.pdf

Galindo, J. (2003). La idea de Ilustración: una exploración y comparación. Punto Cero, 9, 53-59. Recuperado de http://www.academia.edu/1469578/ LA_IDEA_DE_ILUSTRACION_UNA_EXPLOR ACION_Y_COMPARACION_THE_IDEA_OF_IL LUSTRATION_AN_EXPLORATION_AND_CO

\section{MPARISON}

García, C. (1998). La globalización en la sociedad internacional contemporánea.: dimensiones y problemas desde la perspectiva de las Relaciones Internacionales. Recuperado de http://www.ehu.es/ cursosderechointernacionalvitoria/ponencias/ pdf/1998/1998_7.pdf

García, R. (2010). Territorios de la nueva sociedad global. Hacia un nuevo paradigma. Ciudad pazando, 3 (2), 83-92. Recuperado de https:// revistas.udistrital.edu.co/ojs/index.php/cpaz/article/ view/7353/9072

García, R. (2006). Territorios de la nueva sociedad global: hacia un nuevo paradigma. Encuentros académicos internacionales. Recuperado de http:// www.eumed.net/eve/resum/06-12/rmga.htm

Garrido, L. (2011). Habermas y la Teoría de la acción comunicativa. Razón y Palabra, 75. Recuperado de http://www.razonypalabra.org.mx/N/N75/ ultimas/38_Garrido_M75.pdf

Gaytán, P. (2001). Hanna Arendt y la cuestión social. Sociológica, 47, 101-128. Recuperado de http://www.redalyc.org/html/3050/305026541004/

Gonnet, J. (2010). La política desde la teoría de sistemas sociales de Niclas Luhman. Nueva época, año 23, 64, 303-310. Recuperado de http:// www.scielo.org.mx/scielo.php?pid=S018757952010000300014\&script=sci_arttext

Gutiérrez, A. (1998). Público-privado un modo de intervenir en la sociedad global-local. Recuperado de http://rua.ua.es/dspace/bitstream/10045/5798/1/ ALT_06_04.pdf

Heinz S.; Arenas, N. (1995). Lo Global, Lo Local, Lo Hibrido. Aproximaciones a una discusión que comienza. Gestión de las Transformaciones Sociales - MOST, Documentos de debate, 6 . Recuperado de http://www.unesco.org/most/ sonntspa.htm 
LA POLÍTICA EN LA CIVILIZACIÓN CAPITALISTA

Henao, A. (2011). ¿Es la noción de totalitarismo aún relevante? su recepción filosófica en Theodor w. Adorno y Hannah Arendt (Trabajo de posgrado, Universidad Nacional de Colombia. Recuperado de www.bdigital.unal.edu.co/4873/1/

andresfabianhenaocastro.2011.pdf

Heras, L., Morales, C. (2013). Un recorrido en el pensamiento de Hanna Arendt. De la vita contemplativa a la vita activa. Revista Diacrítica, 27 (2), 225-245. Recuperado de http:// webcache.googleusercontent.com/search? $\mathrm{q}=$ cache:N-KIWIqirNoJ:www.scielo.mec.pt/ scielo.php\%3Fscript\%3Dsci_arttext $\% 26$ pid $\%$ 3DS0807-89672013000200014+\&cd=1\&hl=es$419 \& \mathrm{ct}=\mathrm{clnk} \& \mathrm{gl}=\mathrm{co}$

Inda, G. (2008). La Sociología política de Emili Durkheim. La centralidad del problema del estado en sus reflexiones del período 1883-1885 Andamios. Revista de Investigación Social, 4 (8), junio, 135-168. Recuperado de http://www.redalyc.org/ articulo.oa?id=62811458006

Infante, J. (2007). Anthony Giddens. Una interpretación de la globalización. Trayectorias, 9 (23), 5566. Recuperado de Recuperado de http:// www.redalyc.org/pdf/607/60715117007.pdf

Jiménez, A. (2010). Los procesos de globalización e integración económica: retos y oportunidades para el mercadeo internacional de las empresas. Revista Venezolana de Análisis de Coyuntura, 16, (2), 95113. Recuperado de http://www.redalyc.org/ articulo.oa?id=36418856005

Kacowicz, A. (2008). América Latina en el mundo: globalización, regionalización y fragmentación. Nueva Sociedad, 214, 112-123. Recuperado de http://www.nuso.org/upload/articulos/3513_1.pdf

Laborde, M.; Veiga, L. (2010). La integración económica: Desde las zonas de libre comercio hasta la integración política completa. Revista de Antiguos Alumnos del IEEM. Recuperado de http:// socrates.ieem.edu.uy/wp-content/uploads/2011/06/ abc_economia.pdf
Larraín, J. (2014). Reflexiones sobre la teoría social en la actualidad. Economía y Política, 1(2), 73-99. Recuperado de https://dialnet.unirioja.es/descarga/ articulo/6266418.pdf

Lechner, N. (2005). Estado, derecho y gobierno en la sociedad global. Los desafíos de gobernabilidad en una sociedad global. Polis, Revista de la Universidad Bolivariana, 4 (10). Recuperado de http:// www.redalyc.org/articulo.oa?id=30541009

Opazo, J. (2012). Vigencia del pensamiento de Max Weber. Recuperado de http://www.facso.uchile.cl/ publicaciones/sociologia/articulos/05/0506Opazo.pdf

Ozollo, J. (2005) Marx y el estado. Determinaciones sociales del pensamiento de Karl Marx. Ozollo Javier y Libronauta Argentina S.A. Recuperado de bdigital.uncu.edu.ar/objetos_digitales/2687/marx-yel-estado-final-1.pdf

Maesso, M. (2011). La integración económica. Tendencias y nuevos desarrollos de la teoría económica, 858. Recuperado de http://www.revistasice.com/ CachePDF/ICE_858_119-

132_660D0F2D853D0505C9F365F4B9CF7C45.p df

Martínez, J. (2007). La autodeterminación. Anuario de Derechos Humanos. Nueva Época, 8, 325-364). Recuperado de eprints.ucm.es/11378/1/ Autodeterminacion.pdf

Martínez, R. (s.f). La ética económica y política de Max Weber. Recuperado de 200.16.86.50/ digital/658/revistas/vsi/martinezdecarlos2-2.pdf

Meichsner, S. (2007). El campo político en la perspectiva teórica de Bourdieu. Primavera, Tomo 3, 2. Recuperado de http://www.uia.mx/actividades/ publicaciones/iberoforum/3/pdf/sylviam.pdf

Mejía, O. (2011). Teoría crítica, estado autoritario y sociedad global. La heterodoxia marxista y el reto de la globalización. Recuperado de http:// www.nodo50.org/cubasigloXXI/congreso04/ mejia2_310504.pdf 
LA POLÍTICA EN LA CIVILIZACIÓN CAPITALISTA

Merladet, J. (2011). La evolución de la autodeterminación de los pueblos en los últimos cien años. Hermes. Recuperado de http://dialnet.unirioja.es/ descarga/articulo/3780376.pdf

Morales, J. (2011). La nueva integración latinoamericana: Globalización, apertura y dinamismo comercial. Estudios Internacionales. Recuperado de http:// www.rmdd.uchile.cl/index.php/REI/article/ viewFile/15024/19263

Payero, L. (2014). El derecho de autodeterminación de los pueblos. Análisis crítico del marco constitucional español desde la filosofía jurídico - política (tesis de posgrado), Universidad de Oviedo. Recuperado de http:/digibuo.uniovi.es/dspace/ bitstream/10651/28934/6/

TD_LuciaPayeroLopez.pdf

Pérez, H. (s.f). A propósito de los clásicos de la sociología. Recuperado de http:// www.bdigital.unal.edu.co/1344/3/02CAPI01.pdf

Pérez, I, (2012). Identidad nacional y sentido de los jóvenes sobre su nación. Revista latinoamericana de ciencias sociales, niñez y juventud, 10 (2), 871-882, Recuperado de http://www.scielo.org.co/pdf/rlcs/ v10n2/v10n2a07.pdf

Pérez, J. (2001). Sobre la globalización. III ESE, 1, 11-122. Recuperado de http://dspace.unav.es/ dspace/bitstream/10171/7955/1/Notas5.pdf

Prati, M. (2000). Anthony Giddens. La tercera vía. La renovación de la socialdemocracia. Sociohistórica, 7, 327-336. Recuperado de www.memoria.fahce.unlp.edu.ar/art_revistas/ pr.3815/pr.3815.pdf

Robinson, W. (2007). Una teoría sobre el capitalismo global. Producción, clases y Estado en un mundo transnacional. Ediciones desde abajo. Recuperado de http://www.soc.ucsb.edu/faculty/robinson/ Assets/pdf/Una\%20teoria\%20sobre\%20cap\%

20global.pdf

Raveli, K. (2009). ¿Autodeterminación o derecho de autodeterminación?. Recuperado de http:// ecuador.indymedia.org/media/2009/05/28902.pdf

Rojas, I. (1999). Theodor Adorno y la Escuela de Frankfurt. Convergencia, 19, 71-86. Recuperado de http://www.infoamerica.org/documentos_pdf/ adorno02.pdf

Sánchez, S. (1981). El pensamiento jurídico político de Karl Marx. Revista de Derecho Político, 11, 117-140. Recuperado de http://espacio.uned.es:8080/fedora/get/

bibliuned:Derechopolitico-1981-11-331E413C/PDF

Sotelo, I. (1997). El pensamiento político de Jürgen Habermas. En Gimbernat, J. (ed). La filosofía moral y política de Jürgen Habermas. Biblioteca Nueva. Recuperado de http://perrerac.org/alemania/josantonio-gimbernat-ed-la-filosofa-moral-y-polticade-jrgen-habermas-1997/1456/

Urteaga, E. (2010). La teoría de sistemas de Nicklas Luhman. Contrastes. Revista Internacional de Filosofía, 15, 301-317. Recuperado de http:// www.uma.es/contrastes/pdfs/015/ContrastesXV16.pdf

Velazco, D. (s.f). ¿Mandar obedeciendo? Pierre Bourdieu y el campo político. Dossier. Recuperado de http://www.cge.udg.mx/revistaudg/rug24/ boudieu2.html

Zapata, G. (2006). La condición política en Hanna Arendt. Pap. Polit, 11 (2), 505-523. Recuperado de www.scielo.org.co/scielo.php?

script=sci_arttext\&pid $=$ S0122.

Zapata, G. (2012). El espacio público y su fundamento en la libertad. Pensamiento político de Hanna Arendt. Pap. Polit, 171 (1), 159-174. Recuperado de $\quad$ www.scielo.org.co/pdf/papel/v17n1/ v17n1a06.pdf 